\title{
Update van sacrale neuromodulatie voor functiestoornissen van de lage urinewegen
}

\author{
Janine M. W. Janssen · John P. F. A. Heesakkers · Gommert A. van Koeveringe • Desiree M. J. Vrijens · \\ Martijn A. C. Smits
}

Geaccepteerd op: 27 juli 2021 / Published online: 3 september 2021

(C) The Author(s) 2021

\begin{abstract}
Samenvatting Sacrale neuromodulatie (SNM) wordt sinds de jaren 90 van de vorige eeuw toegepast als behandeling voor therapieresistente overactieve blaas of niet-obstructieve urineretentie. In dit artikel wordt het neuromodulatiesysteem, de indicaties en het werkingsmechanisme toegelicht aan de hand van de huidige inzichten en recente publicaties. Tevens worden de nieuwe ontwikkelingen op het gebied van operatietechniek, beleid rond de ingreep en het technisch aspect besproken.
\end{abstract}

Trefwoorden zenuwstimulatie $\cdot$ overactieve blaas . niet-obstructieve retentie

\section{Sacral neuromodulation for lower urinary tract functional dysfunction: an update}

\begin{abstract}
Sacral neuromodulation is an approved treatment for overactive bladder and non-obstructive retention since the nineties of the last century. This article highlights the neuromodulation system, the indications for use, and the working mechanism, on the basis of current insights and recent publications. In addition, the new developments regarding surgery technique, surgical policy and the technical aspects of the system are being discussed.
\end{abstract}

Keywords nerve stimulation - overactive bladder . non-obstructive retention

\footnotetext{
J. M. W. Janssen, PhD ( $₫)$ - prof. dr. J. P. F. A. Heesakkers · prof. dr. G. A. van Koeveringe · dr. D. M. J. Vrijens • drs. M. A. C. Smits $(\varangle)$ afdeling Urologie, MUMC+, Maastricht, Nederland janine.janssen@mumc.nl

drs. M. A. C. Smits $(\bowtie)$

mac.smits@mumc.nl
}

\section{Introductie}

Sacrale neuromodulatie (SNM) wordt sinds de jaren 90 van de vorige eeuw toegepast binnen de urologie als derdelijnsbehandeling voor therapieresistente overactieve blaas en voor niet-obstructieve urineretentie. Sindsdien is de ingreep van een open chirurgische techniek geëvolueerd tot een minder invasieve percutane techniek. De recente ontwikkeling op het gebied van de behandeling met neuromodulatie heeft met name betrekking op de optimalisatie van de patiëntselectie en de chirurgische techniek. Dit artikel betreft de huidige inzichten en recente ontwikkelingen.

\section{Sacrale neuromodulatie}

Bij de behandeling met SNM wordt een elektrode geplaatst op het niveau van de sacrale wortels (S2, S3 of S4). Deze elektrode wordt aangesloten op een implanteerbare pulsgenerator (IPG), die continue elektrische impulsen doorgeeft aan de sacrale wortels. Met deze behandeling kan de functie van de lage urinewegen worden hersteld bij patiënten met een overactieve blaas of niet-obstructieve urineretentie.

Omdat op basis van de individuele patiëntkarakteristieken in onvoldoende mate een uitspraak kan worden gedaan over de succeskans van de behandeling en het een kostbare behandeling betreft, wordt altijd eerst een proefbehandeling verricht. Voor die proefbehandeling zijn twee opties: de percutaneous nerve evaluation (PNE) of de tined lead procedure (TLP).

Bij PNE wordt poliklinisch een tijdelijke elektrode geplaatst nabij de sacrale wortel, die wordt aangesloten op een uitwendige pulsgenerator. In de daaropvolgende periode, doorgaans een week, wordt duidelijk of de proefstimulatie effect heeft. PNE is een laagdrempelige, snelle en goedkope methode als een 
eerste patiëntselectie voor permanente plaatsing van de elektrode. Een succesvolle PNE kan direct worden opgevolgd door definitieve plaatsing van het volledige systeem. Plaatsing gebeurt immers poliklinisch en is weinig invasief.

Bij TLP (eerste fase) wordt direct de definitieve elektrode ingebracht (met weerhaakjes ter fixatie). De positie van deze elektrode (in welk sacraal foramen en tot op welke diepte), wordt middels radiologische doorlichting gecontroleerd. Na een evaluatieperiode van twee tot vier weken kan, als de proefbehandeling succesvol was, in een tweede chirurgische procedure een implanteerbare pulsgenerator worden geplaatst (TLP tweede fase). Treedt geen of onvoldoende verbetering op, dan kan de elektrode worden verwijderd. Met TLP wordt nauwkeuriger getest dan met PNE en bovendien kan de lead in situ blijven wanneer er na een succesvolle testfase op implantatie van de pulsgenerator wordt overgegaan [1].

Sinds de introductie van SNM, wordt het effect van de behandeling geobjectiveerd met mictielijsten. De mictielijsten tijdens de proefbehandeling worden vergeleken met die van de uitgangssituatie. In de internationale literatuur wordt een behandeling succesvol geacht indien de klachten meer dan $50 \%$ verbeteren en dit is ook in Nederland het criterium om tot definitieve implantatie over te gaan.

\section{Indicaties voor SNM}

Sinds 1994 wordt SNM toegepast in de behandeling van therapieresistente overactieve blaas. De initiële behandelingen voor overactieve blaas zijn leefstijladviezen, bekkenfysiotherapie en medicatie. Indien deze falen, kan worden overgegaan op tweede- of derdelijns behandelingsopties. Naast SNM zijn er nog twee andere neuromodulerende behandelingsopties die in deze fase aangeboden kunnen worden, namelijk percutane nervus tibialis stimulatie (PTNS) en blaasinjecties met botulinetoxine. Deze zijn geïndiceerd voor de idiopathische en neurogene overactieve urineblaas (OAB) [2-5]. De behandeling kan voor patiënten met therapieresistente symptomen van $\mathrm{OAB}$ een significante reductie van aandrang, frequency en urgency-incontinentie bieden.

De conservatieve behandeling van niet-obstructieve urineretentie (NOR) bestaat enkel uit drainage van de blaas, middels intermitterende katheterisatie of permanente drainage met een verblijfskatheter. Indien obstructie is uitgesloten als primaire oorzaak van blaasledigingsproblematiek, kan met SNM weer spontane mictie worden bereikt.

Bij $70 \%$ van de patiënten die vanwege een $\mathrm{OAB}$ of NOR een proefbehandeling middels TLP eerste fase ondergaan, is de behandeling succesvol ( $>50 \%$ verbetering van de parameters op de mictielijsten) en volgt definitieve implantatie [6]. Van die patiënten ervaart $70 \%$ na 20 jaar nog steeds een positief effect van de behandeling [7].
SNM is ook in studieverband uitgevoerd voor andere indicaties, zoals mictieklachten van neurogene oorsprong of het blaaspijnsyndroom. De EAU-richtlijn voor neuro-urologie stelt dat SNM een effectieve en veilige behandeling kan zijn voor neurogene blaasfunctiestoornissen. SNM is in de richtlijn echter niet in het behandelingsalgoritme opgenomen, omdat de patiëntenpopulatie te heterogeen is vanwege de verschillende onderliggende neurologische aandoeningen van de patiënten en het gebrek aan RCT's met overtuigende uitkomsten [8, 9].

In de EAU-richtlijn voor neuro-urologie wordt de patiëntenpopulatie ingedeeld op basis van het niveau van de neurologische laesie en welke specifieke disfunctie van de lage urinewegen deze laesie tot gevolg heeft. De patiënten met een suprapontiene laesie presenteren zich met name met een (neurologische) overactieve blaas. De meest onderzochte groep binnen deze categorie zijn patiënten met de ziekte van Parkinson, maar de resultaten van SNM bij deze groep zijn wisselend. Er zijn studies met redelijke resultaten in de testfase (65\% succesvol), die echter bij de helft van de geïmplanteerde patiënten tijdens de follow-up niet beklijven. Tevens zijn er studies met een laag succespercentage tijdens de testfase (25\%). De spreiding van de resultaten komt met name voort uit de vaak kleine subgroepen die worden onderzocht $[8,10,11]$.

De patiënten met spinale laesies, zoals een dwarslaesie, presenteren zich met name met een overactieve blaas en een dyssynergie tussen blaas en sfincter. Bij een incomplete laesie is SNM 100\% succesvol bij zowel urine-incontinentie als urineretentie, maar het succespercentage van $46 \%$ bij patiënten met idiopathische OAB of NOR blijft daar ver bij achter [9-11]. Er is geen indicatie voor SNM bij patiënten met een volledig dwarslaesie [10]. Ook studies bij patiënten met spina bifida laten slechts een zeer laag succespercentage zien $(30 \%)[8,10]$. Een centrale neurologische ziekte als multipele sclerosis (MS) leidt tot blaasfunctiestoornissen met detrusorover-, maar ook onderactiviteit. Vaak is sprake van mengvormen van blaasfunctiestoornissen en zijn de klachten progressief; de resultaten van SNM bij MS zijn dan ook wisselend. Het succespercentage van de testfase ligt tussen 54 en $60 \%$, maar afname van de effectiviteit van de behandeling blijkt vaak voor te komen. SNM bij patiënten met snelprogressieve MS wordt dan ook afgeraden [10-12].

SNM bij blaaspijnsyndroom is onvoldoende onderzocht en ook lange follow-up ontbreekt, vermeldt de EAU-richtlijn. De kans op een succesvolle behandeling van blaaspijnsyndroom is ook duidelijke lager dan van de geregistreerde indicaties, met een slagingspercentage van de proefbehandeling van rond de $40 \%$ [9, 13, 14]. SNM zou kunnen worden ingezet alvorens over te gaan op meer invasieve behandelingen (niveau van bewijs 3; niveau van de aanbeveling zwak), of bij patiënten die ook overactiviteit of blaasledigingsproblematiek hebben [9, 15-17]. 


\section{Werkingsmechanisme}

Met SNM wordt gepoogd de abnormale sensaties en onwillekeurige reflexen te moduleren en de willekeurige controle te herwinnen; dit geldt voor zowel patiënten met $\mathrm{OAB}$ als met NOR. Het exacte werkingsmechanisme van SNM is nog niet geheel duidelijk, maar recent onderzoek naar het blootleggen van het werkingsmechanisme is veelbelovend.

Er wordt verondersteld dat er elektrische stimulatie van zowel afferente als efferente zenuwvezels plaatsvindt. De rol van stimulatie van de efferente zenuwbanen staat hierbij het meest ter discussie. De direct zichtbare bekkenbodemcontracties (anale reflex) bij het inschakelen van de neuromodulator is echter bewijs van efferente stimulatie. In welke mate deze efferente stimulatie bijdraagt aan het effect van de behandeling van NOR is nog onbekend [18].

Voor zover nu bekend berust het effect van SNM bij patiënten met $\mathrm{OAB}$ op inhibitie van de musculus (m.) detrusor, zonder dat die inhibitie invloed heeft op de urethrale weerstand of blaascontractiliteit tijdens de mictie [19]. Daarnaast treedt er verandering op in de blaassensaties. De stimulatie van somatische afferente zenuwen in de sacrospinale wortel, leidt tot modulatie van de betrokken reflexen en hersencentra [19, 20]. Bij OAB-patiënten die zes maanden met neuromodulatie behandeld waren, kon veranderde hersenactiviteit worden gemeten in regio's die een rol spelen bij detrusorhyperactiviteit, het bewustzijn van blaasvulling, aandrang tot mictie en de timing van de mictie. Dit suggereert een centraal effect van SNM [21].

Bij NOR is sprake van een hoge urethrale weerstand, die al dan niet gepaard gaat met verminderde contractiliteit van de $\mathrm{m}$. detrusor en sensatieverlies. Het effect van SNM bij NOR berust vermoedelijk op de blokkade van de inhibitie van de urethrale afferente zenuwvezels. Deze inhibitie resulteert in een bevordering van de blaascontractiliteit, als een omgekeerde guarding reflex [19, 22].

\section{Patiëntselectie}

Tot op heden moet de behandeling met SNM altijd worden voorafgegaan door een proefbehandeling. $\mathrm{Er}$ kan op basis van de karakteristieken van de patiënt geen zekere uitspraak worden gedaan of de behandeling effectief zal zijn. De succeskans van een testbehandeling middels TLP eerste fase met SNM is ongeveer 70\%, zowel bij OAB als bij NOR.

De focus van recent onderzoek op het gebied van SNM ligt met name op de identificatie van de patiënten die goed reageren op de behandeling. Patiëntkarakteristieken als geslacht, leeftijd, body mass index (BMI) zijn allemaal onderzocht als mogelijke predicatieve factoren voor succes van SNM, evenals urodynamische parameters. Een systematische review van de literatuur over voorspellers van succes toonde dat vrouwen beter reageren op SNM dan mannen, waar- bij de complexiteit van disfunctionele mictie bij mannen vermoedelijk een grote rol speelt. Bij $O A B$ is de aanwezigheid van detrusoroveractiviteit op het urodynamisch onderzoek geen (negatieve) voorspeller van succes. Voor NOR geldt dat de mate van hypocontractiliteit samenhangt met de kans op succes: hoe minder contractiliteit, hoe kleiner de kans op succes. Er wordt dan ook afgeraden SNM aan te bieden aan patiënten met a-contractiliteit bij (mobiel) urodynamisch onderzoek [23].

De meeste patiënten met $\mathrm{OAB}$ die een testbehandeling met SNM ondergaan, hebben vaak al een lang behandeltraject doorlopen met onder andere leefstijlaanpassingen, bekkenfysiotherapie en medicatie. Het heeft daarvoor ook al vaak lang geduurd voordat zij met deze klachten een arts consulteerden. Gemiddeld zijn de klachten acht jaar aanwezig vóórdat een derdelijnsbehandeling wordt opgestart [24]. Ook patiënten met NOR draineren vaak al langere tijd de blaas middels intermitterende katheterisatie of een verblijfskatheter alvorens zij worden doorgestuurd voor behandeling met SNM. De duur van klachten bij aanvang van testbehandeling met SNM is eveneens geen predicatieve factor voor succes [24].

De volgorde waarin de drie eerdergenoemde derdelijnsbehandelingen bij therapieresistente $\mathrm{OAB}$ dienen te worden aangeboden, is niet duidelijk. Er is geen eenduidige behandelstrategie die hulp biedt bij deze keuze. Indien de symptomen ook niet reageren op PTNS of blaasinjecties met botulinetoxine is er nog steeds een goede kans dat patiënten succesvol kunnen worden behandeld met SNM; falen van de andere behandelingen is geen voorspeller voor het succes van SNM [25, 26]. Andersom hebben patiënten na falen van SNM ook voldoende kans op een geslaagde behandeling middels botulinetoxine-blaasinjecties [27].

\section{Ontwikkelingen}

Succes van de behandeling is in sterke mate gerelateerd aan de positie van de elektrode ten opzichte van de sacrale zenuwwortels. Daarom wordt veel onderzoek gedaan naar optimale plaatsing van de definitieve elektrode. Een team van experts heeft een gestandaardiseerde techniek voor elektrodeplaatsing opgesteld met optimale positie van de elektrode (plaatsing en controle onder doorlichting) [28]. Studies die de positie van de elektrode koppelden aan succespercentage tonen wisselende resultaten $[29,30]$.

De duur van de testfase met de definitieve elektrode (TLP eerste fase) varieert momenteel in verschillende centra tussen twee en acht weken. Een prospectief opgezette studie toonde dat verbetering van $\geq 50 \%$ gemiddeld na drie dagen en uiterlijk na negen dagen werd gezien bij patiënten met zowel OAB als NOR [31]. Een andere studie wees uit dat een testfase van drie weken een optimaal succespercentage zou geven, gezien de mogelijkheid om de stimulatieparameters te wijzigen [32]. 
Een studie die specifiek is uitgevoerd naar SNMproefbehandeling bij NOR-patiënten gaf aan dat bij deze patiëntencategorie het effect kan optreden tussen 1 en 31 dagen, waaruit het advies volgde om een proefbehandeling van vier weken aan te houden; met een proefbehandeling van slechts twee weken zou een vijfde van de patiënten gemist kunnen worden [33].

\section{Technische ontwikkelingen}

Het neuromodulatiesysteem wordt sinds de introductie in de jaren 90 continu verbeterd en doorontwikkeld. Het belangrijkste doel van deze ontwikkelingen is het reduceren van de aan het systeem gerelateerde problemen bij patiënten. De meest voorkomende complicatie van de behandeling met neuromodulatie is pijn die is gerelateerd aan de positie en locatie van de implanteerbare pulsgenerator (IPG) [4, 34]. Het formaat van de pulsgenerator speelt hierin een belangrijke rol: hoe groter des te meer hinder patiënten ervaren. Sinds 2019 zijn er oplaadbare pacemakers op de markt die evident kleiner zijn dan nietoplaadbare systemen. Ongeveer $7 \%$ van de patiënten rapporteert IPG-gerelateerde pijnklachten, waarvan $2 \%$ een oplaadbare en dus kleinere IPG heeft [35]. Ook zijn bij oplaadbare systemen heroperaties minder frequent nodig: de huidige modellen beloven behoud van de batterijkwaliteit gedurende 15 jaar. Er zijn inmiddels twee soorten op de markt, van Axonics en Medtronic [36, 37].

Het verrichten van een MRI bij patiënten met een oudere neuromodulator leidt vaak tot discussie; de fabrikant raadt dit af. Toch is het effect van een MRI bij deze patiëntengroep wel onderzocht. Meerdere studies toonden aan dat een MRI bij een patiënt met een intact maar ouder systeem in situ niet leidt tot klachten of een verminderde werking van het systeem $[38,39]$. Bovendien leek een MRI van een intact systeem niet tot opwarming van de lead te leiden [40]. De nieuwe systemen (sinds 2019) zijn bovendien goedgekeurd voor gebruik in de MRI-scan. Dit houdt enerzijds in dat ook patiënten bij wie herhaaldelijke MRI-scans nodig zijn nu in aanmerking komen voor een neuromodulator en patiënten bij het ondergaan van ongeplande, noodzakelijke MRI-onderzoeken niet meer gehinderd worden door de aanwezigheid van het systeem. Anderzijds biedt het de mogelijkheid om het effect van neuromodulatie op het centraal zenuwstelsel te onderzoeken en daardoor mogelijk meer te weten te komen over de werking van zo'n systeem. Dit zou in de toekomst kunnen leiden tot een betere indicatiestelling bij deze patiëntengroep.

De bediening van de neuromodulatoren heeft in technisch opzicht de afgelopen decennia ook een grote sprong voorwaarts gemaakt. Zowel patiënt als behandelend team kan het systeem tegenwoordig benaderen via een applicatie op een mobiele telefoon, wat het gebruiksgemak aanzienlijk heeft verbeterd.

\section{Conclusie}

SNM is een succesvolle derdelijnsbehandeling bij OAB en NOR. Andere indicaties worden niet standaard aangeraden in de richtlijnen, maar kunnen na zorgvuldige afweging overwogen worden. Recent onderzoek leidt tot optimale leadplaatsing en de duur van de testfase zou voor OAB-patiënten naar twee weken kunnen worden ingekort. Het is echter aan te raden voor NOR-patiënten een testfase van vier weken aan te houden.

Doordat er zowel oplaadbare als oplaadvrije systemen op de markt zijn, kan een op de patiënt afgestemde behandeling worden gekozen. Wij adviseren om niet alleen rekening te houden met de voorkeur van de patiënt, maar ook te kiezen voor het oplaadbare systeem bij jonge patiënten of patiënten bij wie risico op pijnklachten van IPG hoog is (zoals bij weinig lichaamsvet of bij rolstoelgebonden patiënten). De oplaadvrije variant kan gunstig zijn voor patiënten bij wie bediening van het systeem lastig is of die niet wekelijks aan het opladen willen denken.

Open Access This article is distributed under the terms of the Creative Commons Attribution 4.0 International License (http://creativecommons.org/licenses/by/4.0/), which permits unrestricted use, distribution, and reproduction in any medium, provided you give appropriate credit to the original author(s) and the source, provide a link to the Creative Commons license, and indicate if changes were made.

\section{Literatuur}

1. Van Kerrebroeck PEV, Marcelissen TAT. Sacral neuromodulation for lower urinary tract dysfunction. World J Urol. 2012;30(4):445-50.

2. Thüroff JW, Abrams P, Andersson KE, et al. EAU guidelines on urinary incontinence. Eur Urol. 2011;59(3):387-400.

3. Gupta P, Ehlert MJ, Sirls LT, Peters KM. Percutaneous tibial nerve stimulation and sacral neuromodulation: an update. Curr Urol Rep. 2015;16(2):4-9.

4. Sukhu T, Kennelly MJ, Kurpad R. Sacral neuromodulation in overactive bladder: a review and current perspectives. Res Rep Urol. 2016;8:193-9.

5. Moore CK, Rueb JJ, Derisavifard S. What is new in neuromodulation? Curr Urol Rep. 2019;20(9):55.

6. Van Kerrebroeck PEV, van Voskuilen AC, Heesakkers JPFA, et al. Results of sacral neuromodulation therapy for urinary voiding dysfunction: outcomes of a prospective, worldwide clinical study. J Urol. 2007;178(5):2029-34.

7. Gandhi S, Gajewski JB, Koziarz A, Almutairi S, Ali A, Cox A. Long-term outcomes of sacral neuromodulation for lower urinary tract dysfunction: a 23-year experience. Neurourol Urodyn. 2021;40(1):461-9.

8. BlokB, Castro-DiazD, DelPopolo G, etal. EAU guidelines on neuro-urology. Arnhem: EAUGuidelines Office; 2020.

9. El-Azab AS, Siegel SW. Sacral neuromodulation for female pelvic floor disorders. Arab J Urol. 2019;17(1):14-22.

10. Averbeck MA, Moreno-Palacios J, Aparicio A. Is there a role for sacral neuromodulation in patients with neurogenic lower urinary tract dysfunction? Int Braz J Urol. 2020;46(6):891-901.

11. Chaabane W, Guillotreau J, Castel-Lacanal E, et al. Sacral neuromodulation for treating neurogenic bladder dysfunc- 
tion: clinical and urodynamic study. Neurourol Urodyn. 2011;54(2):547-50.

12. Wöllner J, Krebs J, Pannek J. Sacral neuromodulation in patients with neurogenic lower urinary tract dysfunction. Spinal Cord. 2016;54(2):137-40.

13. Mahran A, Baaklini G, Hassani D, et al. Sacral neuromodulation treating chronic pelvic pain: a meta-analysis and systematic review of the literature. Int Urogynecol J. 2019;30:1023-35.

14. Ammirati E, Giammò A, Manassero A, Carone R. Neuromodulation in urology, state of the art. Urol J. 2019;86(4):177-82.

15. Engeler D, Baranowski AP, Berghmans B, et al. EAU guidelines on chronic pelvic pain. Eur Urol. 2004;46(6):681-9.

16. Rahnama'i MS, Marcelissen T, Apostolidis A, et al. The efficacy of botulinum toxin A and sacral neuromodulation in the management of interstitial cystitis (IC)/bladder pain syndrome (BPS), what do we know? ICI-RS 2017 think thank, Bristol. Neurourol Urodyn. 2018;37:S99-107.

17. Rahnamai MS, Javan A, Vyas N, etal. Bladder pain syndrome and interstitial cystitis beyond horizon: reports from the global interstitial cystitis/bladder pain society (gibs) meeting2019 Mumbai-India. Anesth Pain Med. 2020;10(3):1-8.

18. Vaganée D, Fransen E, Voorham J, van de Borne S, Voorham-van der Zalm P, de Wachter S. Behind the scenes: an electromyographic interpretation of the pelvic floor contractions seen by the naked eye upon lead stimulation in sacral neuromodulation patients. Neurourol Urodyn. 2019;38(S3):S445-8.

19. de Wachter S de, Vaganee D, Kessler TM. Sacral neuromodulation: mechanism of action. Eur Urol Focus. 2020;6(5):823-5.

20. Leng WW, Chancellor MB. How sacral nerve stimulation neuromodulation works. Urol Clin North Am. 2005;32(1):11-8.

21. Blok BFM, Groen J, Bosch JLHR, Veltman DJ, Lammertsma AA. Different brain effects during chronic and acute sacral neuromodulation in urge incontinent patients with implanted neurostimulators. BJU Int. 2006;98(6):1238-43.

22. Amend B, Matzel KE, Abrams P, de Groat WC, Sievert K. How does neuromodulation work. Neurourol Urodyn. 2011;30:762-5.

23. Jairam R, Drossaerts J, Marcelissen T, van Koeveringe G, Vrijens D, van Kerrebroeck P. Predictive factors in sacral neuromodulation - a systematic review. Urol Int. 2021; https://doi.org/10.1159/000513937.

24. Jairam R, Drossaerts J, Van Koeveringe G, Van KerrebroeckP. The impact of duration of complaints on successful outcome of sacral neuromodulation. Urol Int. 2017;99(1):51-5.

25. Berthelot LP, Peyronnet B, Cornu JN, et al. Do failure of posterior tibial nerve stimulation precludes to use sacral neuromodulation in patient with overactive bladder? Int Neurourol J. 2019;23(4):287-93.

26. Yang G, Xu Y, Qu G, Zhang Y. Refractory overactive bladder patients who chose sacral neuromodulation therapy after failed onabotulinumtoxin A treatment: a systematic review and meta-analysis. PLoSONE. 2020;15(3):1-10.

27. Baron M, Perrouin-Verbe MA, Lacombe S, Paret F, Le Normand L, Cornu JN. Efficacy and tolerance of botuli- num toxin injections after sacral nerve stimulation failure for idiopathic overactive bladder. Neurourol Urodyn. 2020;39(3):1012-9.

28. Matzel KE, Chartier-Kastler E, Knowles CH, et al. Sacral neuromodulation: standardized electrode placement technique. Neuromodulation. 2017;20(8):816-24.

29. Adelstein SA, Lee W, Gioia K, et al. Outcomes in a contemporary cohort undergoing sacral neuromodulation using optimized lead placement technique. Neurourol Urodyn. 2019;38(6):1595-601.

30. Jairam R, Marcelissen T, Van Koeveringe G, Van Kerrebroeck P. Optimal lead positioning in sacral neuromodulation: Which factors are related to treatment outcome? Neuromodulation. 2017;20(8):830-5.

31. Jairam R, Drossaerts J, Marcelissen T, Van Koeveringe G, Van Kerrebroeck P. Onset of action of sacral neuromodulation in lower urinary tract dysfunction. What is the optimal duration of test stimulation? J Urol. 2018;199(6):1584-90.

32. TilborghsS, van deBorneS, VaganéeD, deWin G, deWachter S. A supervised 3 weeks test phase in sacral neuromodulation with a 1-year followup. JUrol. 2021;205:206-12.

33. Elneil S, Abtahi B, Pharm D, Helal M, Digesu A, Gonzales G. Optimizing the duration of assessment of stage-1 sacral neuromodulation in nonobstructive chronic urinary retention. Neuromodulation. 2014;17:66-71.

34. Tutolo M, Ammirati E, van der Aa F. What is new in neuromodulation? Eur Urol Focus. 2018;4(2):49-53.

35. de Wachter S, Knowles CH, Elterman DS, et al. New technologies and applications in sacral neuromodulation: an update. Adv Ther. 2020;37(2):637-43.

36. Pezzella A, McCrery R, Lane F, et al. Two-year outcomes of the ARTISAN-SNM study for the treatment of urinary urgency incontinence using the Axonics rechargeable sacral neuromodulation system. Neurourol Urodyn. 2021;40(2):714-21.

37. Blok B, Van KerrebroeckP, de Wachter S, et al. A prospective, multicenter study of a novel, miniaturized rechargeable sacral neuromodulation system: 12-month results from the RELAX-OAB study. Neurourol Urodyn. 2019;38(2):689-95.

38. Guzman-Negron JM, Pizarro-Berdichevsky J, Gill BC, Goldman HB. Can lumbosacral magnetic resonance imaging be performed safely in patients with a sacral neuromodulation device? An in vivo prospective study. J Urol. 2018;200(5):1088-92.

39. Gill BC, Pizarro-Berdichevsky J, Bhattacharyya PK, et al. Real-time changes in brain activity during sacral neuromodulation for overactive bladder. J Urol. 2017;196(6):1379-85.

40. Quirouet A, Bhattacharyya PK, Dielubanza EJ, Gill BC, Jones SE, Goldman HB. Sacral neuromodulation device heating during lumbar and pelvic magnetic resonance imaging aphantom study. Urology. 2017;107:61-6.

prof. dr. John P.F.A. Heesakkers, uroloog

prof. dr. Gommert A. van Koeveringe, uroloog

dr. Desiree M.J. Vrijens, uroloog

drs. Martijn A.C. Smits, uroloog 